\title{
The effects of high-energy feeding on energy balance and growth in infants with congenital heart disease and failure to thrive
}

\author{
BY MARK JACKSON AND ELIZABETH M. E. POSKITT \\ Institute of Child Health, University of Liverpool, Royal Liverpool Childrens Hospital, Alder Hey, \\ Eaton Road, Liverpool L12 $2 A P$
}

(Received 21 March 1990 - Accepted 20 July 1990)

\begin{abstract}
Failure to thrive (FTT) in infants with congenital heart disease (CHD) can be attributed to their low energy intakes and high resting energy expenditures. Energy intake, energy expenditure and growth were studied in infants with CHD on normal formula feeds and then on feeds supplemented with glucose polymer to see whether supplementation improved energy retention and growth. Mean gross energy intakes increased by $31.7 \%$ on high-energy feeding and mean weight gain improved from $1.3 \mathrm{~g} / \mathrm{kg}$ per d on control to $5.8 \mathrm{~g} / \mathrm{kg}$ per $\mathrm{d}$ on high-energy feeding. Resting oxygen consumption ( $\dot{V}_{\mathrm{O}_{2}} \mathrm{ml} / \mathrm{kg}$ per min) was not significantly different on the two feeding regimens, although respiratory quotient rose on highenergy feeding reflecting the increased carbohydrate intake. Estimated energy costs of growth on highenergy feeding fell within the previously described range for normal infants. It is recommended that infants with CHD known to be associated with FTT are fed on high-energy diets from the time of diagnosis in order to optimize growth.
\end{abstract}

Congenital heart disease: Energy balance in infancy: Failure to thrive: High-energy feeding

Children with congenital heart disease (CHD) commonly fail to thrive (Mehziri \& Drash, 1962; Feldt et al. 1969; Menahem, 1972; Menon \& Poskitt, 1985). They present in infancy as chronic malnutrition with reduced subcutaneous fat, wasted muscles and linear growth retardation. Histopathological studies show liver changes suggestive of malnutrition in infants who die (Naeye, 1965). Failure to thrive (FTT) usually results from the combination of inadequate nutrient intakes, malabsorption, failure to utilize food for growth in the presence of gross anoxia, and increased nutrient requirements. Several studies have shown that FTT associated with high resting metabolic rates is particularly likely in infants with pulmonary hypertension and congestive cardiac failure (Krauss \& Auld, 1975; Baum et al. 1980; Menon \& Poskitt, 1985). These infants may consume energy intakes within recommended requirements for weight but consistently less than requirements for both expected weight-for-age and expected needs for catch-up growth (Lees et al. 1965; Menon \& Poskitt, 1985).

Various methods have been used to increase the energy intakes of infants with CHD and to assess whether growth improves as a result. Nocturnal or continuous feeding by gavage are effective short-term methods (Yahav et al. 1985; Bougle et al. 1986). However, it is neither desirable nor always practical to keep young infants with CHD and FTT in hospital for prolonged periods to increase weight, so feeding methods need to be safe, simple and able to be practised at home. High-energy feeding should also be acceptable to very young infants since the prevention or limitation of FTT by early management is preferable to treatment once FTT has developed. If brain growth and function are at risk from poor nutrition in CHD (Naeye, 1965), the greatest risk is likely to be in early life when brain cell multiplication and development are most rapid (Dobbing, 1981). Prolonged periods of malnutrition may inhibit both brain growth and infants' opportunities to learn from the 
environment, thus increasing the probability of developmental delay. Ability to withstand the trauma of surgery should be greatest in infants with least nutritional stress. Avoiding, or at least limiting, FTT in infancy is part of the management of infants with CHD.

We have studied the effect of increasing the energy content of feeds to see how this improves energy retention and weight gain in CHD infants. It seemed possible that where there existed adverse factors for growth such as anoxia and poor peripheral perfusion, energy supplementation might be dissipated as increased metabolism rather than as tissue deposition in growth. We have followed not only energy intakes in these infants but energy expenditures as well.

\section{METHODS}

Infants admitted to the Royal Liverpool Childrens Hospital (City Branch), with FTT and CHD were studied when their cardiac condition had been stabilized and changes in medical management or surgery, or both, were not anticipated. FTT was defined as failure to gain weight at the expected rate as indicated by growth standards (Vaughan \& Litt, 1987). Most children also had weights below the third centile weight for age at entry to the study.

Infants were studied for two balance periods of $3 \mathrm{~d}$ by methods similar to those of Menon \& Poskitt (1985). During the balance periods, energy intakes were estimated from weighed food intakes and collection and weighing of all food losses as posset, vomit and spillage. Urine and stools were collected for analysis of energy excreted or not absorbed. Energy expenditure was measured daily during each balance period by indirect calorimetry. During the first period (control), infants continued to be given their usual infant formula (and solids if introduced). Energy density of the feeds was then increased over $3 \mathrm{~d}$ to at least $125 \%$ standard formula by the addition of glucose polymer (Caloreen; Roussel Laboratories, Uxbridge, Middx). After a further day for stabilization at the new energy level, the energy balance (high-energy) studies were repeated. Fig. 1 outlines the pattern of balance periods in relation to energy density of feeds.

Stools were separated from urine by using preweighed nappy liners positioned into tightly fitting disposable nappies. The beginning and end of each stool collection were marked by feeding sterile carmine marker (BDH, Poole, Dorset) with the first feed of the balance period and the first feed after completion of the balance period. The time between the first appearance of these markers represented the stool collection period. Gross stool output was calculated from reweighing the soiled liners. All pads, urine soaked nappies and soiled liners were stored in labelled plastic bags at $-20^{\circ}$ until analysis.

\section{Energy content of feeds, stools, urine, posset and vomit}

One extra formula feed was prepared for each infant's $24 \mathrm{~h}$ batch of feeds. Sample weaning solids were reconstituted to the fed composition using the sample formula. Representative stool samples were achieved by scraping stools from the individual liners. Soiled absorbent pads and urine-soaked nappies were macerated with a known volume of water and allowed to stand for $24 \mathrm{~h}$ to equilibrate, and then crudely filtered. Portions of the filtrate were finely filtered under vacuum. Portions of feeds, stools and combined urine-posset-vomit samples were frozen at $-20^{\circ}$ and freeze-dried, and the energy contents determined by ballistic bomb calorimetry (Miller \& Payne, 1959).

\section{Respiratory gas exchange}

Infants were studied on two occasions in each $24 \mathrm{~h}$ during the balance periods: for $1 \mathrm{~h}$ before a feed, and for $1.5 \mathrm{~h}$ after a feed. Infants lay on a mattress with a Perspex chamber covering head and thorax. Room air was drawn through a loosely fitting plastic hood using constant negative pressure and into the Perspex chamber (Fig. 2). Flow-rates were at least 


$\begin{array}{lllllllllllll}\text { Day ... } & 0 & 1 & 2 & 3 & 4 & 5 & 6 & 7 & 8 & 9 & 10 & 11 \\ \text { Stool marker given } \ldots & 1 & & & 1 & & & & & & & & \end{array}$

Weighed feeds/

urine collection ..
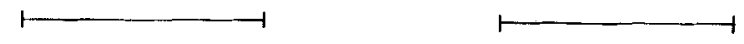

Formula energy

density ( $\%$ control) .

Marker appears

in stool ...

$\downarrow$

$\downarrow$

Stool collection ...

Respratory gas exchange studies (pre- and post-feed)

Antropometry ...

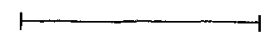

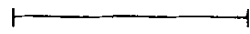

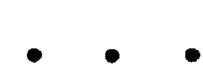

Fig. 1. Plan of energy balance periods on standard and high-energy feeds.

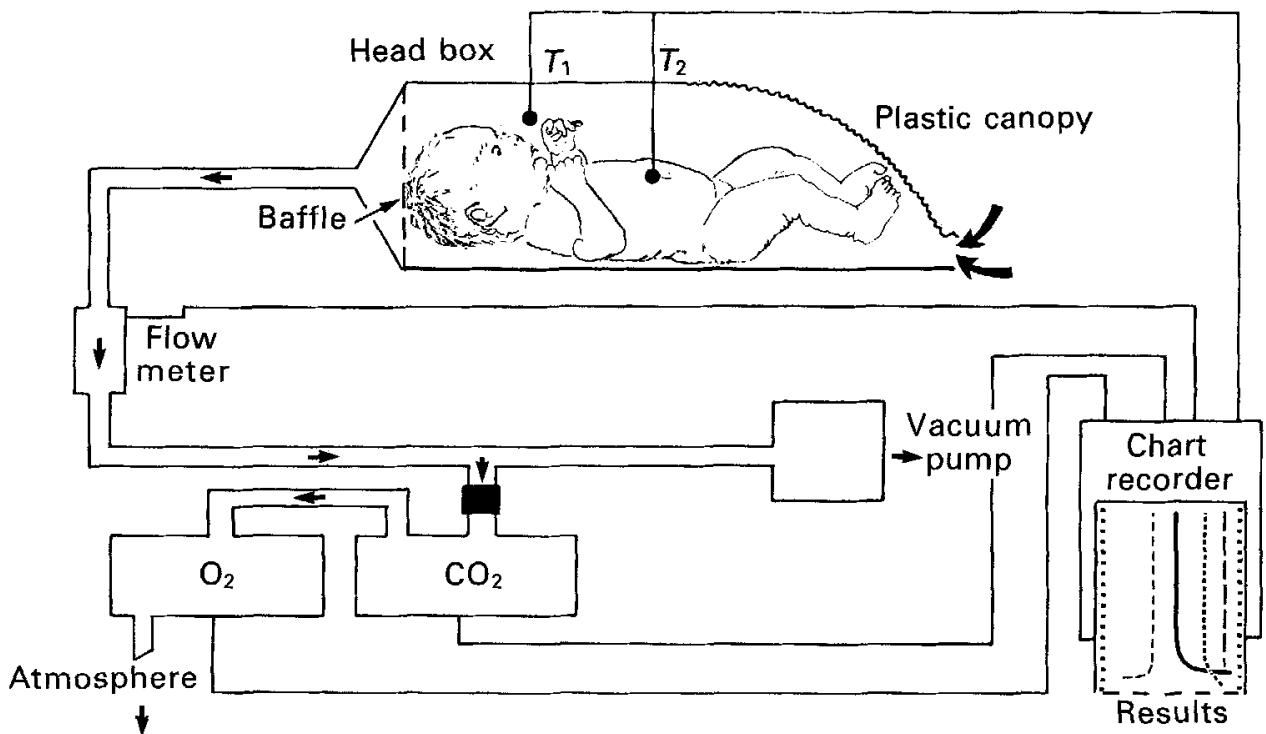

Fig. 2. Equipment and configuration used in the measurement of infant oxygen consumption. Air is drawn under a plastic canopy and into the system by a vacuum pump. Flow-rate is measured, and a sample of the gas analysed for carbon dioxide and $\mathrm{O}_{2}$ fraction. All values, including box and abdominal temperature $\left(T_{1}\right.$ and $\left.T_{2}\right)$ are directed to the chart recorder for later analysis.

ten times the estimated minute volumes of the infants (Lister et al. 1974), ensuring an adequate oxygen supply and rapid removal of carbon dioxide. The exit gases were drawn through a mass flow meter (Chell Instruments; Amersham, Bucks) which provided an accurate measure of flow-rate corrected to standard temperature and pressure. Some of the mixed exit gases were dried by passing through an excess of calcium chloride before 
estimation of gas fractions. Volumetric changes as a consequence of drying were likely to be small and were ignored. Respiratory gases were measured by infra-red $\mathrm{CO}_{2}$ analyser ( $\mathrm{PK}$ Morgan Ltd, Chatham, Kent), and serially connected paramagnetic $\mathrm{O}_{2}$ analyser (Servomex, Crowborough), both previously calibrated with room air and test gases spanning the expected range. Chamber air temperature and infants' abdominal skin temperature were monitored continuously; temperatures did not vary by more than $0.5^{\circ}$ throughout the study periods.

Gas exchange studies included the full range of infant activity, scored as 0 sleeping, 1 awake and quiet, 2 awake and active and 3 crying. These findings were recorded together with exit gas fractions, temperatures and flow-rates on an on-line multichannel chart recorder (Chessell Ltd, Worthing, Sussex). Mean $\mathrm{O}_{2}$ consumption $\left(\dot{V}_{\mathrm{O}_{2}}\right)$ and $\mathrm{CO}_{2}$ production $\left(\dot{V}_{\mathrm{CO}_{2}}\right)$ for each of the activity levels were calculated by planimetry of the area beneath the curves of the relevant gas fractions and flow-rates.

Differences in diffusion coefficient at the respiratory membrane were accounted for by application of Haldane's correction (Cotes, 1968). Respiratory quotient (RQ) was calculated as mean $\dot{V}_{\mathrm{CO}_{2}}$ divided by mean $\dot{V}_{\mathrm{O}_{2}}$ for each activity level. Energy expenditures at each activity level were calculated by multiplication of the relevant $\dot{V}_{\mathrm{O}_{3}}$ by the appropriate energy equivalent for the observed RQ (Lentner, 1981). Total daily energy expenditure (TDEE) was estimated by weighting energy expenditure for each activity as a proportion of total study time and extrapolating results to $24 \mathrm{~h}$.

\section{Anthropometry}

Nude weight was recorded daily throughout the balance periods. Weight changes on days in hospital preceding the control balance, and days in hospital following the high-energy balance (when high-energy feeding continued) were also recorded. Supine length, occipitofrontal circumference (OFC), and biceps, triceps, suprailiac and subscapular skinfolds were measured (Cameron, 1984) at the beginning and end of each balance period.

Percentage body mass index (\% BMI; Cole, 1979) was calculated as weight $/(\text { length })^{2}$ divided by weight at the 50 th centile-for-age/(length at the 50 th centile-for-age) $)^{2} \times 100 \%$. Expected weight-for-length, weight-for-age and length-for-age were also calculated. Standards from the National Center for Health Statistics were used throughout (Vaughan \& Litt, 1987). Skinfolds are expressed as the logarithm of the summed four skinfolds measured $(\log$ TSFT).

\section{Statistical analysis}

All data were initially tested for normality of distribution. Non-Gaussian data were transformed using logarithmic corrections. The matched pairs Student's $t$ test was used where appropriate. Data untransformable to Normal distributions were compared using the Mann-Whitney $U$ test for ranked scores. Regression analysis was performed using the method of least squares.

\section{RESULTS}

\section{Infants}

Table 1 lists diagnoses in the fourteen CHD infants (three male, eleven female). Mean age of the group was 0.23 (SE $0 \cdot 10)$ years.

\section{Energy intake and weight gain}

Except for one infant receiving a soya-bean-based formula, all infants were fed on standard cow's-milk-based formulas. Only two infants received 'solid' foods in addition to formula.

Table 2 shows gross energy intakes and energy losses in stools, urine, posset and vomit for all infants during the control and high-energy studies. On high-energy supplementation, 
Table 1. Age, sex and diagnosis of infants studied

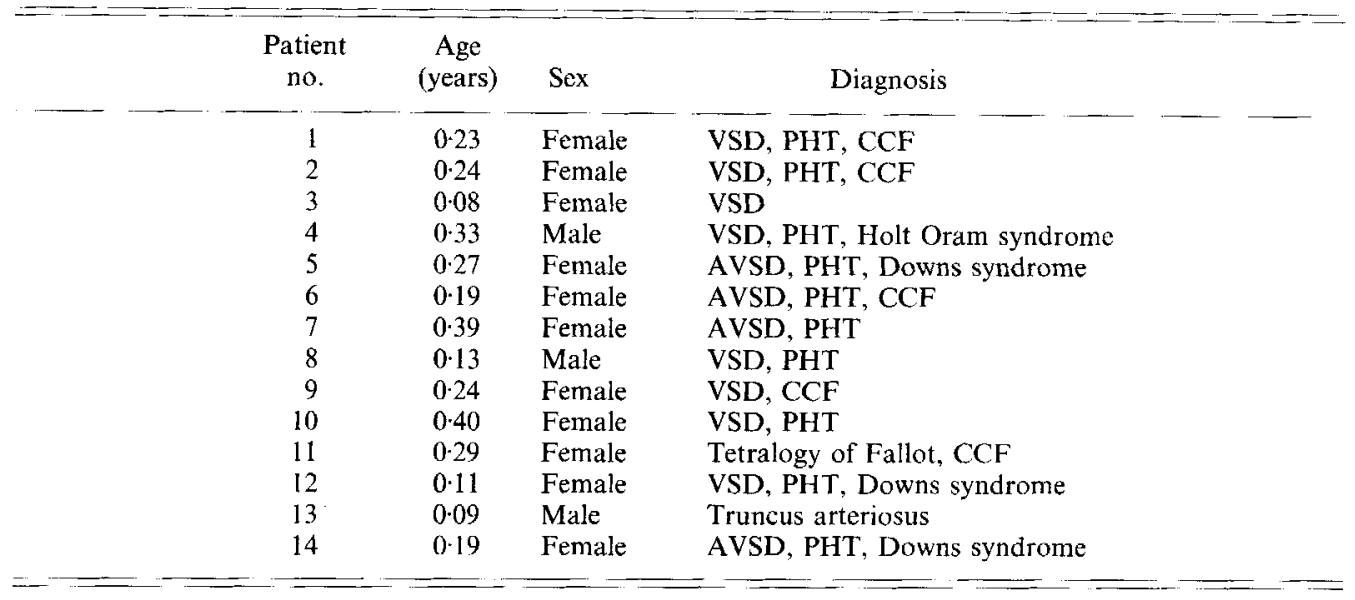

VSD, ventricular septal defect; PHT, pulmonary hypertension; CCF, congestive cardiac failure; AVSD, atrioventricular septal defect.

mean gross energy intake increased by $31.7 \%(P \leqslant 0.001)$ from 88.5 (SE 4.5$) \%$ of recommended daily allowance (RDA) (Department of Health and Social Security, 1979) to 116.8 (SE 5.5 ) \% of RDA. Energy intakes expressed as percentages of RDA correlated significantly with weight gains over the high-energy balance periods (Fig. 3). Energy losses in stools and combined urine-posset-vomit (Table 2) were not significantly different between control and high-energy studies. Metabolizable energy intakes (MEI) expressed both in absolute terms and as percentages of gross energy fed improved on high-energy feeds: from 362 (SE 23) kJ $/ \mathrm{kg}$ per d to 505 (SE 31) kJ/kg per d $(P \leqslant 0.001)$, and from 83 (SE 4$) \%$ to 87 (SE 3$) \%(P \leqslant 0.01)$, respectively.

During the control balance, MEI was not significantly correlated with weight gain $(r 0.28)$. During the high-energy balance, a highly significant relationship $(r 0.83)$ was demonstrated (Fig. 4). From this, the energy requirement for zero weight gain (maintenance energy) could be calculated at $327 \mathrm{~kJ} / \mathrm{kg}$ per $\mathrm{d}$ and each $\mathrm{g}$ weight gain was associated with the retention of $31 \mathrm{~kJ}$ energy.

\section{Growth}

Table 3 shows mean weight, length, OFC, $\log$ TSFT and \% BMI for each infant during the two balance periods. Mean expected weight-for-age was 61.3 (SE 2.2) \%, height-for-age 91.8 (SE 1.3 ) $\%$ and weight-for-height 75.1 (SE 1.9) $\%$ at the time of the control study. Mean weight gains were increased significantly $(P \leqslant 0.001)$ from $1.3(\mathrm{sE} 0.7) \mathrm{g} / \mathrm{kg}$ per d (control) to $5.8(\mathrm{SE} 1.2) \mathrm{g} / \mathrm{kg}$ per $\mathrm{d}$ (high-energy). Weight-for-age, height-for-age and weight-forheight increased (\%) with high-energy feeding: 62.5 (SE 2.3), 91.9 (SE 2.3) and 77.6 (SE 2.1) respectively but only differences in weight-for-height were significant $(P \leqslant 0.001)$. Outside the periods of intensive study, mean daily weight gain to mid control balance period from a median of $8 \mathrm{~d}$ (range 1-15) before the balance was -0.6 (SE 0.7$) \mathrm{g} / \mathrm{kg}$ per d, and mid highenergy balance period to a median of $8 \mathrm{~d}$ (range $1-56$ ) after the balance was $4.8(\mathrm{SE} 0.6) \mathrm{g} / \mathrm{kg}$ per d $(P \leqslant 0 \cdot 001)$.

Mean \% BMI also increased between control and high-energy studies (Table 3 ) but the increase was not statistically significant. Mean OFC between the balance periods increased $(P \leqslant 0.001)$ and mean change in $\log$ TSFT was increased following supplementation $(P \leqslant 0.05)$. 
Table 2. The 24 h energy balance results in infants* with congenital heart disease and failure to thrive given normal feeds or feeds with increased energy level

\begin{tabular}{|c|c|c|c|}
\hline $\begin{array}{c}\text { Patient } \\
\text { no. }\end{array}$ & $\begin{array}{l}\text { Gross energy } \\
\text { intake }(\mathrm{kJ} / \mathrm{kg})\end{array}$ & $\begin{array}{l}\text { Stool energy } \\
\text { losses }(\mathrm{kJ} / \mathrm{kg})\end{array}$ & $\begin{array}{l}\mathrm{u} / \mathrm{p} / \mathrm{v} \text { energy } \\
\text { losses }(\mathrm{kJ} / \mathrm{kg})\end{array}$ \\
\hline \multicolumn{4}{|l|}{ Control } \\
\hline 1 & 469 & 29 & 16 \\
\hline 2 & 543 & 35 & 19 \\
\hline 3 & 432 & 26 & 17 \\
\hline 4 & 431 & 31 & 11 \\
\hline 5 & 368 & 62 & 19 \\
\hline 6 & 452 & 47 & 14 \\
\hline 7 & 340 & 28 & 12 \\
\hline 8 & 346 & 30 & 15 \\
\hline 9 & 634 & 82 & 75 \\
\hline 10 & 302 & 31 & 7 \\
\hline 11 & 488 & 52 & 29 \\
\hline 12 & 431 & 241 & 11 \\
\hline 13 & 462 & 34 & 13 \\
\hline 14 & 466 & 104 & 7 \\
\hline Mean & 440 & 60 & 19 \\
\hline $\mathrm{SE}$ & 23 & 15 & 5 \\
\hline \multicolumn{4}{|l|}{ High-energy } \\
\hline 1 & 546 & 26 & 20 \\
\hline 2 & 572 & 38 & 25 \\
\hline 3 & 587 & 19 & 26 \\
\hline 4 & 496 & 35 & 15 \\
\hline 5 & 539 & 52 & 28 \\
\hline 6 & 642 & 40 & 21 \\
\hline 7 & 441 & 56 & 6 \\
\hline 8 & 796 & 52 & 9 \\
\hline 9 & 716 & 69 & 17 \\
\hline 10 & 379 & 17 & 7 \\
\hline 11 & 567 & 70 & 13 \\
\hline 12 & 603 & 277 & 10 \\
\hline 13 & 672 & 42 & 7 \\
\hline 14 & 562 & 42 & 6 \\
\hline Mean & 580 & 60 & 15 \\
\hline$S E$ & 29 & 17 & 2 \\
\hline $\begin{array}{l}\text { Statistical } \\
\text { significance } \\
\text { of difference }\end{array}$ & $P \leqslant 0.001$ & & \\
\hline
\end{tabular}

$\mathrm{u} / \mathrm{p} / \mathrm{v}$, Urine, posset and vomit.

* For details of subjects, see Table 1 .

Respiratory gas exchange

Resting heart rate, resting respiratory rate and the proportion of each balance period spent sleeping during the gas-exchange studies were not significantly different between the control and high-energy balance periods.

Table 4 lists sleeping $\dot{V}_{\mathrm{O}_{2}}$ and $\mathrm{RQ}$ for each infant during the control and high-energy balance periods. Mean $\dot{V}_{\mathrm{O}}$, whilst asleep and during activity (control $12 \cdot 1$ (SE 0.5 ) $\mathrm{ml} / \mathrm{kg}$ per min, high-energy $12.0(\mathrm{SE} 0.5) \mathrm{ml} / \mathrm{kg}$ per min) did not change significantly between control and high-energy studies. Mean sleeping $\dot{V}_{\mathrm{O}_{2}}$ tended to be higher in those infants with documented pulmonary hypertension.

Mean sleeping RQ rose significantly $(P \leqslant 0.001)$ following carbohydrate supplemen- 


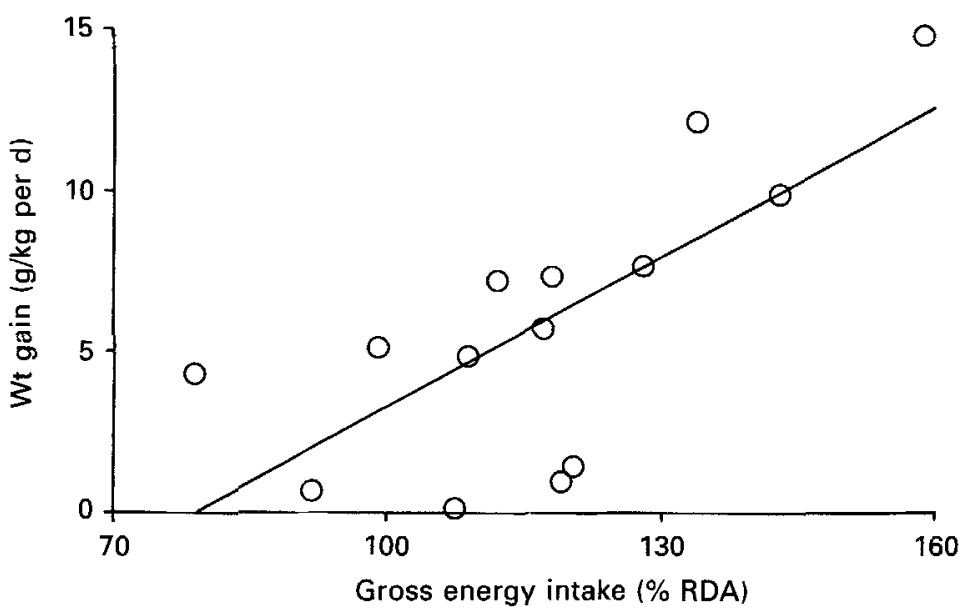

Fig. 3. Regression relationship of gross energy intake (expressed as percentage recommended daily allowance (RDA); Department of Health and Social Security, 1979), against weight gain for the high-energy balance period in infants with congenital heart disease and failure to thrive. For details of experimental procedures, see p. 132. $y=0 \cdot 1582 x+12 \cdot 6691, r 0 \cdot 72 ;$ SE of estimate $3 \cdot 22 ; P \leqslant 0 \cdot 005$.

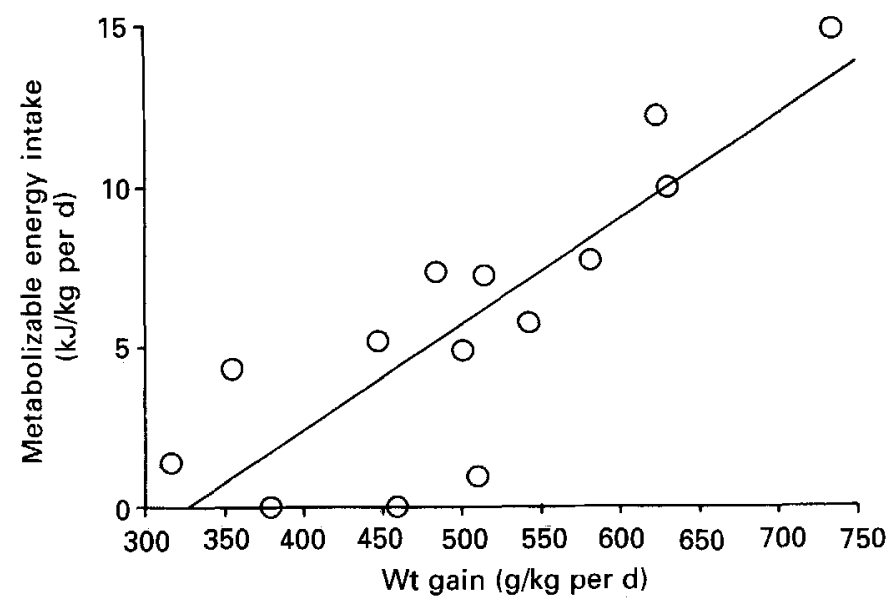

Fig. 4. Regression relationship of weight gain against metabolizable energy intake for the high energy balance period in infants with congenital heart disease and failure to thrive. For details of experimental procedures, see p. 132

$$
y=0.0325 x+10.6323, r 0.83 ; \text { SE of estimate } 2.58 ; P \leqslant 0.001 .
$$

tation. Mean RQ during periods of activity was similarly affected (control 0.83 (SE 0.01), high-energy 0.90 (SE 0.02 ), $P \leqslant 0.001$ ).

\section{Energy available for growth and activity}

Table 5 shows MEI, TDEE, 'spare' energy and weight gain for each infant during control and high-energy balances. Energy expenditures showed no significant differences between the balance periods. 'Spare' energy available for growth, calculated as MEI minus that energy estimated as utilized in basal and activity energy expenditure from the gas-exchange studies, was significantly increased by energy supplementation $(P \leqslant 0.001)$. 
Table 3. Weight, length, occipito-frontal circumference, logarithm of the sum of four skinfolds measured and percentage body mass index during control and high-energy balance periods for infants with congenital heart disease and failure to thrive

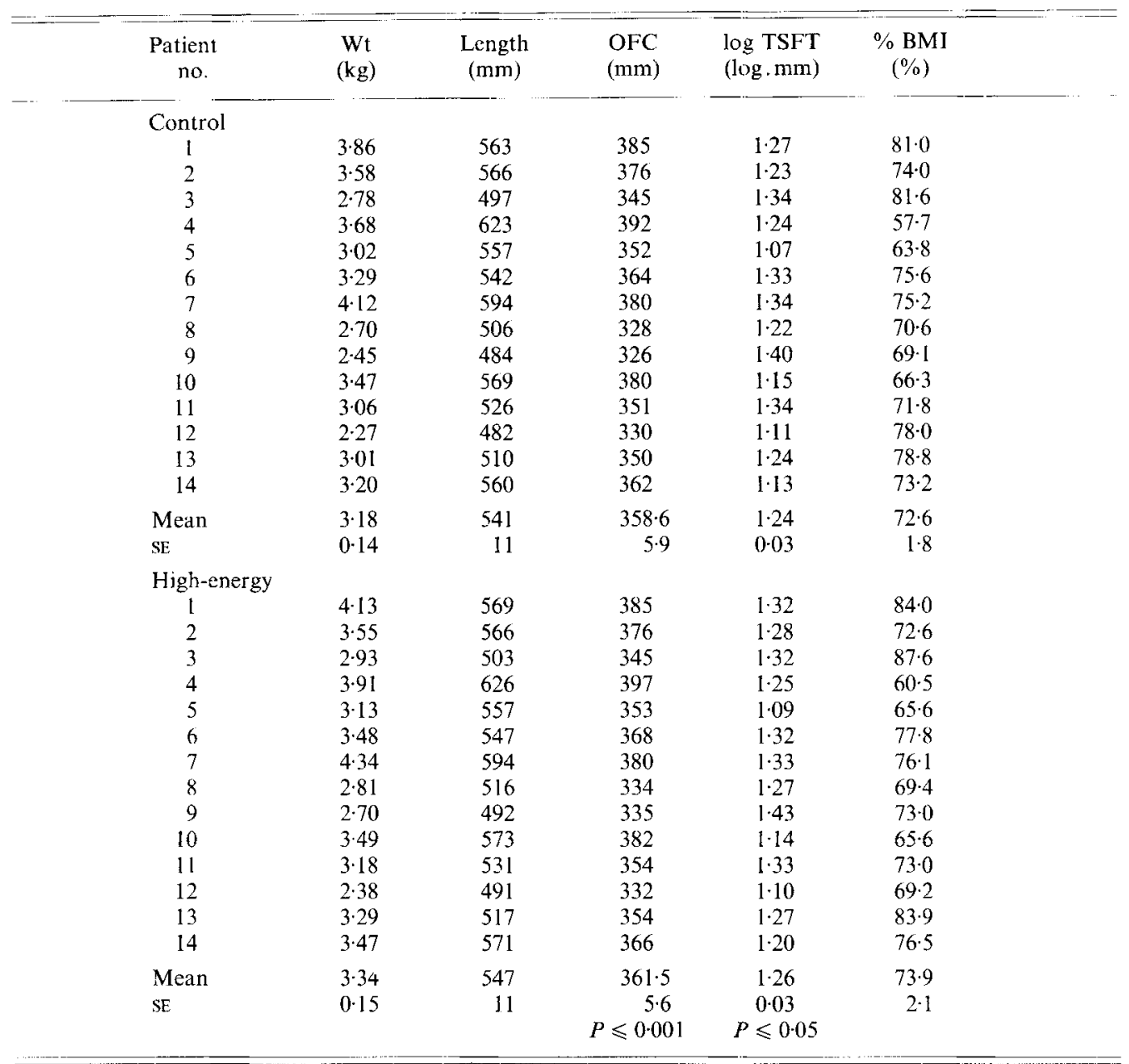

OFC, occipito-frontal circumference; $\log$ TSFT, logarithm of the sum of four skinfolds measured; \% BMI, percentage body mass index (see p. 134).

\section{DISCUSSION}

The present study confirms what several studies have shown previously, namely that some infants with CHD have high resting metabolic requirements as well as low energy intakes (Lees et al. 1965; Stocker et al. 1972; Huse et al. 1975; Menon \& Poskitt, 1985). FTT is thus explained as a consequence of deficiency between energy retention and energy requirements. Our study shows that it is practical to increase energy retention by increasing the energy density of feeds with glucose polymer. Energy supplementation in this way does not lead to increased nutrient losses through urine, posset and vomit or malabsorption. More significantly, weight gain improves, although even with MEI at $140 \%$ of control levels, few children achieved the $10 \mathrm{~g} / \mathrm{kg}$ per d weight gain desirable for catch-up growth in this age group (Ashworth \& Millward, 1986). Changes in length in these children were small and 
Table 4. Sleeping oxygen consumption $\left(\dot{\mathrm{V}}_{O_{3}} ; \mathrm{ml} / \mathrm{kg}\right.$ per min) and respiratory quotient $(R Q)$ for the control and high-energy balance periods for infants with congenital heart disease and failure to thrive

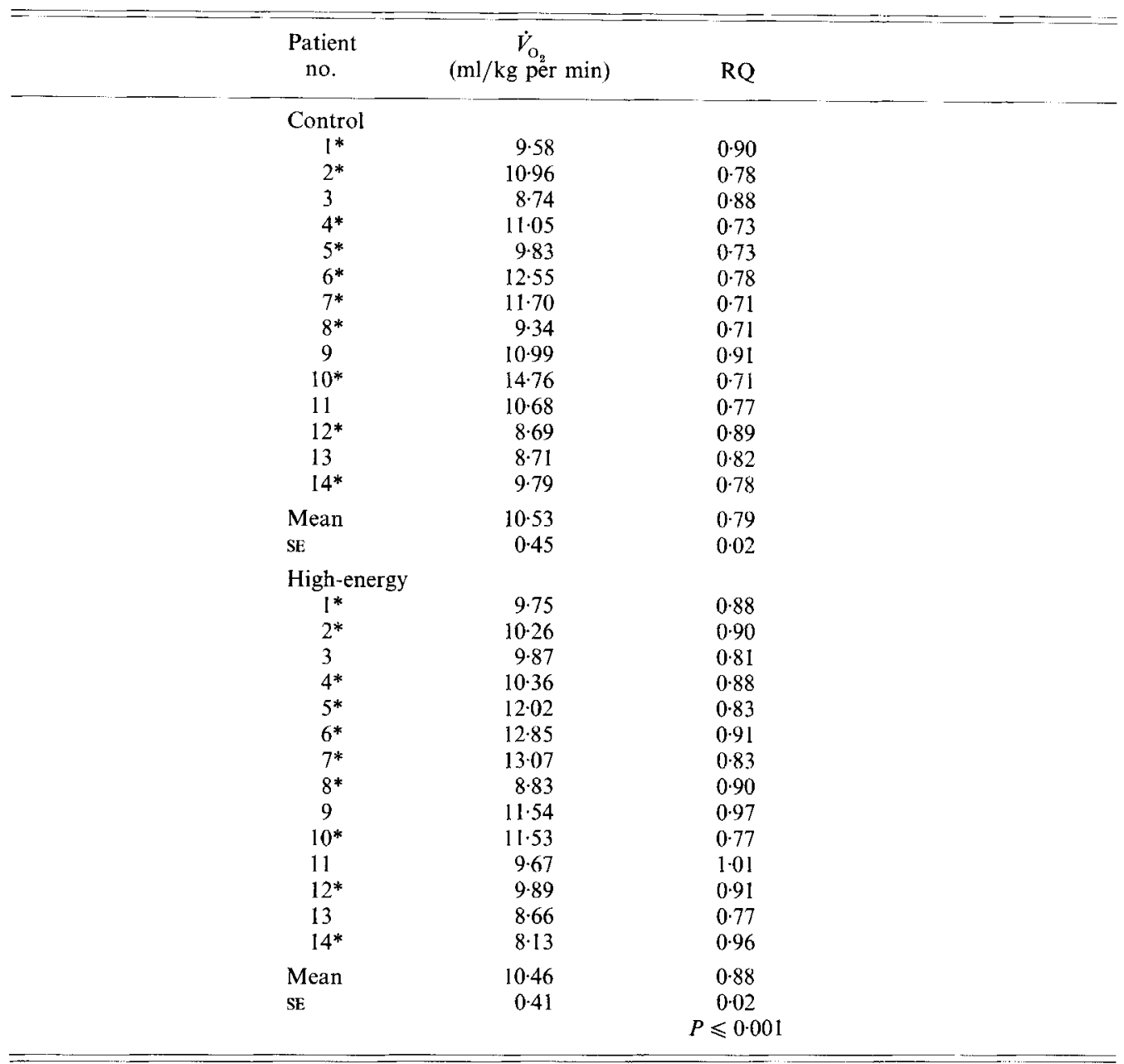

* Pulmonary hypertension.

due to difficulties in making precise measurements in this age group, we cannot comment on the effect of high-energy feeding on linear growth.

Continuous nasogastric infusion of energy at 1.4-1.8 times measured metabolic rate has demonstrated a good anabolic response without change in $\dot{V}_{\mathrm{O}_{2}}$ in adults with congestive heart failure (Heymfield \& Casper, 1989). Similarly, high-energy feeding did not significantly alter resting $\mathrm{O}_{2}$ consumption in our infants. RQ rose on high-energy feeding, indicating a relatively greater proportion of carbohydrate being used as the energy substrate.

We could detect no measurable post-prandial increase in thermogenesis during either control or high-energy feeding. There are several possible explanations for this. Others have pointed out that, because of frequent feeds, infants never achieve basal metabolism before feeding (Freymond et al. 1986). Thus, any post-prandial increase in $\dot{V}_{\mathrm{O}_{2}}$ will be relatively 
Table 5. Metabolizable energy intake ( $M E I)$, total daily energy expenditure (TDEE), 'spare' energy available for growth and weight gain for the control and high energy balance periods for infants with congenital heart disease and failure to thrive

\begin{tabular}{|c|c|c|c|c|}
\hline $\begin{array}{l}\text { Patient } \\
\text { no. }\end{array}$ & $\begin{array}{c}\text { MEI } \\
(\mathrm{k} J / \mathrm{kg})\end{array}$ & $\begin{array}{l}\text { Estimated } \\
\text { TDEE } \\
(\mathrm{kJ} / \mathrm{kg})\end{array}$ & $\begin{array}{l}\text { 'Spare' energy } \\
(\mathrm{kJ} / \mathrm{kg})\end{array}$ & $\begin{array}{c}\text { Balance wt } \\
\text { gain } \\
(\mathrm{g} / \mathrm{kg})\end{array}$ \\
\hline \multicolumn{5}{|l|}{ Control } \\
\hline 1 & 424 & 358 & 66 & $4 \cdot 3$ \\
\hline 2 & 489 & 336 & 153 & -1.9 \\
\hline 3 & 388 & 283 & 105 & $-1 \cdot 1$ \\
\hline 4 & 389 & 364 & 25 & $5 \cdot 4$ \\
\hline 5 & 287 & 365 & -78 & -0.7 \\
\hline 6 & 391 & 381 & 11 & $1 \cdot 0$ \\
\hline 7 & 300 & 425 & -125 & $-1 \cdot 1$ \\
\hline 8 & 301 & 343 & -42 & -0.6 \\
\hline 9 & 477 & 378 & 99 & -0.1 \\
\hline 10 & 264 & 299 & -35 & $-0 \cdot 1$ \\
\hline 11 & 408 & 352 & 55 & $4 \cdot 4$ \\
\hline 12 & 178 & 258 & -80 & $0 \cdot 0$ \\
\hline 13 & 415 & 294 & $12 \mathrm{I}$ & 6.7 \\
\hline 14 & 356 & 344 & 12 & 1.6 \\
\hline Mean & 362 & 341 & 20 & $1 \cdot 3$ \\
\hline SE & 23 & 12 & 23 & $0 \cdot 7$ \\
\hline \multicolumn{5}{|c|}{ High-energy } \\
\hline 1 & 500 & 335 & 165 & 4.9 \\
\hline 2 & 510 & 310 & 200 & 1.0 \\
\hline 3 & 543 & 313 & 229 & 5.7 \\
\hline 4 & 447 & 351 & 96 & $5 \cdot 1$ \\
\hline 5 & 458 & 393 & 66 & $0 \cdot 0$ \\
\hline 6 & 581 & 421 & 160 & 7.7 \\
\hline 7 & 379 & 408 & -29 & 0.0 \\
\hline 8 & 735 & 312 & 423 & $14 \cdot 8$ \\
\hline 9 & 630 & 446 & 184 & $9 \cdot 9$ \\
\hline 10 & 355 & 266 & 89 & 43 \\
\hline 11 & 484 & 295 & 189 & $7 \cdot 3$ \\
\hline 12 & 316 & 304 & 12 & 1.4 \\
\hline 13 & 623 & 341 & 282 & $12 \cdot 2$ \\
\hline 14 & 515 & 332 & 182 & $7 \cdot 2$ \\
\hline Mean & 505 & 345 & 161 & $5 \cdot 8$ \\
\hline \multirow[t]{2}{*}{$\mathrm{SE}$} & 31 & 14 & 31 & 1.2 \\
\hline & $P \leqslant 0.01$ & & $P \leqslant 0.001$ & $P \leqslant 0.00$ \\
\hline
\end{tabular}

small compared with premeal $\dot{V}_{O_{0}}$. The infants in our study were being fed at least every $4 \mathrm{~h}$ or more frequently. Differences between premeal and post-meal $\mathrm{O}_{2}$ consumption might be expected to be 3-9\% of the meal's metabolizable energy in infants fed every $3 \mathrm{~h}$ (Freymond et al. 1986). On high-energy feeding these increases might be in the region of $2-6 \mathrm{~kJ} / \mathrm{kg}$ per $3 \mathrm{~h}$. Differences in activity of the infants before and after feeding could mask such small changes. Brooke \& Ashworth (1972) showed increased thermogenesis post-prandially in proportion to the rates of weight gain in children recovering from malnutrition. Only children growing at rates of greater than $4 \mathrm{~g} / \mathrm{kg}$ per $\mathrm{d}$ continued to show increased postprandial thermogenesis in their study.

From the regression of MEI and weight gain it is possible to make some estimate of the energy required to maintain basal metabolism and the energy cost of growth in these children. We do not have the information to relate each child's weight gain to different levels of energy intake. Regressing energy intakes and weight gains of the infants on high- 
energy feeding provides an estimate of energy needs for nil weight gain (maintenance energy requirement) of $327 \mathrm{~kJ} / \mathrm{kg}$ per $\mathrm{d}$. The estimated energy cost of growth $(31 \mathrm{~kJ} / \mathrm{g})$ is within the range 8-45 kJ/g quoted by Ashworth \& Millward (1986). Our relatively high value for the energy cost of growth might suggest predominant deposition of fat. This is corroborated by the significantly increased skinfold thicknesses and is to be expected in early catch-up growth (Ashworth \& Millward, 1986).

We have studied only the effects of increasing energy intakes on growth. It could be argued that we should have given a more balanced mixture of nutrients. However, energy deficiency is probably the most important nutrient deficiency in these children. There is little clinical evidence for protein deficiency and urea levels are often high, suggesting poor utilization of nitrogen due to small amounts of energy available for growth. Also, carbohydrate supplementation is cheaper than supplementation with fat or protein.

Our estimates of TDEE are inevitably incomplete. In order to have more complete estimates of TDEE it would be necessary to monitor respiratory gas exchange over $24 \mathrm{~h}$, or to record activity over the full $24 \mathrm{~h}$ and relate this to previously determined $\dot{V}_{\mathrm{O}_{2}}$ at these activity levels. Shorter periods of observation can only give vague estimates of TDEE which must vary in how close they are to real expenditure, depending on how individual activity varies throughout the day. In premature infants estimates over $6 \mathrm{~h}$ appear to be practical and have a mean error of estimating TDEE of $0.9 \%$ and a mean absolute error of $5.6 \%$ (Bell et al. 1986). With $2 \mathrm{~h}$ measurement periods in premature infants the mean error was $-2.8 \%$ and mean absolute error $8.6 \%$ (Bell et al. 1986). Shultze et al. (1986), again studying growth of premature infants, concluded that periods of respiratory gas exchange made for less than a complete post-prandial period have little value in estimating long-term $\dot{V}_{\mathrm{O}_{2}}$. Our studies, by spanning the feeding periods, although not including gas exchanges during feeds, covered a full cycle from meal-to-meal during each day of study.

There are few estimates of TDEE in normal infants of this age. A study of normal breastfed infants where TDEE was estimated by the doubly labelled water method (Lucas et al. 1987) showed mean TDEE to be 280 (SE 30) kJ/kg per d at 5 weeks and 300 (SE 10) kJ/kg per $d$ at 11 weeks of age. Weight gains in these two age groups were 36.5 (SE 2.5$) \mathrm{g} / \mathrm{d}$ and $25 \cdot 6(\mathrm{SE} 3 \cdot 1) \mathrm{g} / \mathrm{d}$ respectively. Another study estimated TDEE of infants without a tendency to become overweight as 323 (SE 12) kJ/kg per d (Roberts et al. 1988). These values are less than those recorded in the infants in our study and refer to infants growing at normal rates and, presumably, normal activity. The contrast with the poor weight gain and higher TDEE of our infants is striking. It would be our subjective impression that our infants were less active than normal in the usual physical activities of crying, voluntary limb movement and feeding.

The children in the present study showed varying degrees of FTT, and had a variety of cardiac conditions. Inherent potential for growth may have varied since the study included some children with Down's syndrome who tend to be short even in the absence of associated CHD. Work in animals, confirmed in man, suggests that maintenance metabolic costs in normal individuals are approximately 1.5 times basal metabolism. Brooke et al. (1979), studying premature infants, found maintenance energy expenditure only $1 \cdot 2$ times resting metabolism. In the present study the estimated energy cost of maintenance was only 1.06 times resting metabolism. It would seem that little energy is available for, or directed towards, growth.

Why should infants with CHD have high resting metabolism? One of the problems relating energy intakes to body-weight in these infants is the abnormal body composition as most had a high lean body mass.

Increased cardiac mass may also explain the elevated resting $\dot{V}_{\mathrm{O}_{2}}$. In adults with severe aortic stenosis, $\dot{V}_{\mathrm{O}_{2}}$ by the hypertrophied heart may account for $32.4 \%$ as opposed to $10.8 \%$ total $\dot{V}_{\mathrm{O}_{2}}$ (Pittman \& Cohen, 1964). Infants with corresponding conditions of severe aortic 
stenosis and coarctation of the aorta are likely to die or receive surgical correction before they have developed FTT. This may explain why it is particularly infants with right ventricular hypertrophy (usually secondary to pulmonary hypertension) who show the most significantly elevated resting $\mathrm{O}_{2}$ consumption.

The present study suggests that infants with types of CHD known to be associated with FTT require gross energy intakes probably in excess of $120 \%$ recommended for bodyweight in order to achieve satisfactory rates of growth. Since the daily energy intake necessary for normal growth is less than that required to achieve catch-up growth, early initiation of high-energy feeding seems desirable. Weight and length monitoring should determine whether energy supplementation is appropriate or whether it is leading to excessive fat gain. Transient obesity in some infants with CHD may be a risk worth taking to avoid poor brain growth or unfavourable surgical outcome.

The authors would like to thank Drs Arnold, Leung, Qureshi, Walsh and Wilkinson and Miss McKay for the opportunity to study their patients; the nursing staff of the cardiac wards at RLCH (City Branch); and the staff of the milk kitchen, RLCH (City Branch).

MJ was supported by a grant from the Mersey Region Health Authority.

\section{REFERENCES}

Ashworth, A. \& Millward, D. J. (1986). Catch up growth in children. Nutritional Reviews 44, $157-163$.

Baum, D., Beck, R., Kodama, A. \& Brown, B. (1980). Early heart failure as a cause of growth and tissue disorders in children with congenital heart disease. Circulation 62, 1145-1151.

Bell, E. F., Rios, G. R. \& Wilmoth, P. K. (1986). Estimation of 24-hour energy expenditure from shorter measurement periods in premature infants. Pediatric Research 20, 646-649.

Bougle, D., Iselin, M., Kahyat, A. \& Duhamel, J.-F. (1986). Nutritional treatment of congenital heart disease. Archives of Disease in Childhood 61, 779-801.

Brooke, O. G., Alvear, J. \& Arnold, M. (1979). Energy retention, energy expenditure, and growth in healthy immature infants. Pediatric Research 13, 215-220.

Brooke, O. G. \& Ashworth, A. (1972). The influence of malnutrition on the postprandial metabolic rate and respiratory quotient. British Journal of Nutrition 27, 407-415.

Cameron, N. (1984). The Measurement of Human Growth, pp. 56-99. Bristol: Croom Helm.

Cole, T. J. (1979). A method of assessing age-standardized weight-for-height in children seen cross sectionally. Annals of Human Biology 6, 249-268.

Cotes, J. E. (1968). Lung Function: Assessment and Application in Medicine, pp. 36-37. London: Blackwell Scientific Publications.

Department of Health and Social Security (1979). Recommended Daily Amounts of Food Energy and Nutrients for Groups of People in the United Kingdom. Report on Social Subjects no. 15. London: H.M. Stationery Office.

Dobbing, J. (1981). Later development of the brain and its vulnerability. In Scientific Foundations of Paediatrics, 2nd ed, pp. 744-759 [J. Davis and J. Dobbing, editors]. London: William Heinemann.

Feldt, R. H., Strickler, G. B. \& Weidman, W. H. (1969). Growth of children with congenital heart disease. American Journal of Diseases of Children 117, 573-579.

Freymond, D., Schutz, Y., Decombaz, J., Micheli, J.-L. \& Jequier, E. (1986). Energy balance, physical activity and thermogenic effect of feeding in premature infants. Pediatric Research 20, 638-645.

Heymfield, S. B. \& Casper, K. (1989). Congestive heart failure: clinical management by use of continuous nasoenteric feeding. American Journal of Clinical Nutrition 50, 539-544.

Huse, D. M., Feldt, R. H., Nelson, R. A. \& Novak, L. P. (1975). Infants with congenital heart disease. American Journal of Diseases of Children 129, 65-69.

Krauss, A. N. \& Auld, P. A. M. (1975). Metabolic rate of neonates with congenital heart disease. Archives of Disease in Childhood 50, 539-541.

Lees, M. H., Bristow, J. D., Griswold, H. E. \& Olsmsted, R. W. (1965). Relative hypermetabolism in infants with congenital heart disease and undernutrition. Pediatrics 36, 183-191.

Lentner, C. (1981). Energy expenditure. In Geigy Scientific Tables, vol. 1, Units of Measurement, Body Fluids, Composition of the Body, Nutrition, pp. 228-231. Basle: Ciba Geigy.

Lister, G., Hoffman, J. I. E. \& Rudolph, A. M. (1974). Oxygen uptake in infants and children: a simple method for measurement. Pediatrics 53, 656-662.

Lucas, A., Ewing, G., Roberts, S. B. \& Coward, W. A. (1987). How much energy does the breast fed infant consume and expend? British Medical Journal 295, 75-77.

Mehziri, A. \& Drash, A. (1962). Growth disturbance in congenital heart disease. Journal of Pediatrics 61, 418-429. 
Menahem, S. (1972). The clinical growth of infants and children with ventricular septal defects, Australian Paediatric Journal 8, 1-15.

Menon, G. \& Poskitt, E. M. E. (1985). Why does congenital heart disease cause failure to thrive? Archives of Disease in Childhood 60, 1134-1139.

Miller, D. S. \& Payne, P. R. (1959). A ballistic bomb calorimeter. British Journal of Nutrition 13, 501-508.

Naeye, R. L. (1965). Organ and cellular development in congenital heart disease and in alimentary nutrition. Journal of Pediatrics 67, 447-458.

Pittman, J. G. \& Cohen, P. (1964). The pathogenesis of cardiac cachexia. New England Journal of Medicine 271, 403-409.

Roberts, S. B., Savage, J., Coward, W. A., Chew, B. \& Lucas, A. (1988). Energy expenditure and intake in infants born to lean and overweight mothers. New England Journal of Medicine 318, 461-466.

Schultze, K., Stefanski, M., Masterson, J., Kashyap, S., Sanocka, U., Forsyth, M., Ramakrishnan, R. \& Dell, R. (1986). An analysis of the variability in estimates of bioenergetic variables in preterm infants. Pediatric Research 20, $422-427$.

Stocker, F. P., Wilkoff, W., Miettinen, O. S. \& Nadas, A. S. (1972). Oxygen consumption in infants with heart disease. Journal of Pediatrics 80, 43-51.

Vaughan III, V. C. \& Litt, I. F. (1987). Developmental pediatrics: growth and development. In Nelson Textbook of Pediatrics, pp. 6-24 [R. E. Behrman and V. C. Vaughan, editors]. Philadelphia: W. B. Saunders and Co.

Yahav, J., Avigad, S., Frand, M., Shem-Tov, A., Barzilay, Z., Linn, S. \& Jonas, A. (1985). Assessment of intestinal and cardiorespiratory function in children with congenital heart disease on high-calorie formulas. Journal of Pediatric Gastroenterology and Nutrition 4, 778-785. 